\title{
Mapping Global Mortality and Affected Population Risks for Multiple Natural Hazards
}

\author{
Peijun Shi ${ }^{1,2,3} \cdot$ Xu Yang ${ }^{1,3} \cdot$ Wei $\mathrm{Xu}^{2,3} \cdot$ Jing'ai Wang ${ }^{2,4}$
}

Published online: 18 March 2016

(c) The Author(s) 2016. This article is published with open access at Springerlink.com

\begin{abstract}
Substantial reduction in both mortality from and the number of people affected by natural hazards by 2030 are two principal targets that can be measured to assess global progress toward meeting the goals of the Sendai Framework for Disaster Risk Reduction 2015-2030 (SFDRR). Based on existing research of expected annual multi-hazard intensity $\left(M_{h}\right)$ of 11 hazards at the $0.5^{\circ} \times 0.5^{\circ}$ grid scale in the World Atlas of Natural Disaster Risk, including earthquake, volcanic eruption, landslide, flood, storm surge, tropical cyclone, sand and dust storm, drought, heat wave, cold wave, and wildfire, a vulnerability model involving $M_{h}$ and GDP per capita was developed to estimate the mortality level and scale of affected populations in 2005-2015 and 2020-2030. Global mortality and affected population risks were then mapped at the $0.5^{\circ} \times 0.5^{\circ}$ grid scale and the mortality and affected population rates were ranked at the national scale. The results show that most countries can achieve the target of reducing the mortality and affected population rates. Countries with increasing rates such as Bangladesh and Madagascar, where the coping capacity for natural hazard
\end{abstract}

Peijun Shi

spj@bnu.edu.cn

1 State Key Laboratory of Earth Surface Processes and Resource Ecology, Beijing Normal University, Beijing 100875, China

2 Key Laboratory of Environmental Change and Natural Disasters of Ministry of Education, Beijing Normal University, Beijing 100875, China

3 Academy of Disaster Reduction and Emergency Management, Ministry of Civil Affairs and Ministry of Education, Beijing 100875, China

4 Key Laboratory of Regional Geography, Beijing Normal University, Beijing 100875, China risks cannot keep pace with the increase of $M_{h}$ and the growth of exposure, should be the "hotspots" of concern in global disaster risk reduction. The method proposed to quantitatively calculate the mortality and affected population risks can provide scientific and technical support for assessing global and national/regional progress in achieving the outcome and goal of the SFDRR.

Keywords Affected population - Global scale . Multi-hazards $\cdot$ Mortality $\cdot$ Sendai framework

\section{Introduction}

Natural disasters are now increasing in scale and frequency. Together with climate change, natural hazards significantly impede progress towards sustainable development (UNISDR 2015). Since 2005, the number of people affected by natural disasters has reached more than 1.5 billion and is still increasing (UNISDR 2015). There remains, therefore, a great challenge for global disaster risk reduction. Following the Hyogo Framework for Action (UNISDR 2005), the Sendai Framework for Disaster Risk Reduction 2015-2030 (SFDRR) aims to achieve substantial reduction in disaster risk and loss of life, livelihood, and health, as well as to diminish the wastage of the economic, physical, social, cultural, and environmental assets of persons, businesses, communities, and countries over the next 15 years (UNISDR 2015). Assessment of global progress in achieving this outcome and goal is one of several bases that will support implementation of the SFDRR.

With this aim in mind, the SFDRR took mortality and affected population as two of seven important national targets and indicators that contribute to achieving the 
Sendai Framework's goals. The targets are to "substantially reduce global disaster mortality by 2030 , aiming to lower average per 100,000 global mortality between 2020 and 2030 compared to 2005-2015"; and "substantially reduce the number of affected people globally by 2030 , aiming to lower the average global figure per 100,000 during 2020-2030 compared to during 2005-2015" (UNISDR 2015, Targets). To achieve these aims, an accurate and quantitative measurement is required to understand the impacts of natural disasters on human society, to study the vulnerability of different societies to such disasters, and to frame new and appropriate disaster reduction policies.

Risk assessment of multiple natural hazards (multihazards for short) evaluates the total risk of various types of natural hazards that occur in a given region and in a certain period of time (Shi 2009). Globally, analysis of spatial patterns and changes in natural hazard occurrence has been pivotal to tackling global climate change and to formulating integrated risk governance policies. Since the 1980s, many organizations around the world have carried out in-depth research on multi-hazard risk assessment and have attempted to map risk at both regional and global scales.

In 2004, the United Nations Development Programme (UNDP) developed a disaster risk index to calculate the multiple risks of mortality due to earthquakes, cyclones, floods, and droughts. The index was based on the vulnerability derived from eight social indicators: economy, type of economic activity, dependency on and quality of the environment, demography, health and sanitation, early warning capacity, education, and overall development at the national level (UNDP 2004). In the same year, the World Bank and Columbia University evaluated the vulnerability to multiple hazards and calculated the risk of mortality and economic losses caused by six hazards. These hazards included earthquakes, volcanic eruptions, landslides, floods, droughts, and cyclones, which were assessed based on the historical loss data available in the Emergency Events Database (EM-DAT) at a $2.5^{\circ} \times 2.5^{\circ}$ grid scale (Dilley et al. 2005). In 2013, the United Nations University (UNU) evaluated vulnerability at the national level based on 28 indicators from three societal perspectives: sensitivity, coping capacity, and adaptability. The UNU calculated the mortality risk due to five hazards (earthquakes, floods, cyclones, droughts, and sea-level rise), and used the product of exposure and vulnerability to generate the world risk index (UNU-EHS 2013). In 2014, the European Union Joint Research Centre (JRC) calculated a dynamic risk ranking of 191 countries by evaluating hazards and exposure, vulnerability, and coping capacity based on 53 indicators using the developed Index for Risk Management (INFORM) model (JRC 2014).
The reliability and accuracy of multi-hazard risk assessment depends greatly on how the relationship between hazard intensity and loss is quantitatively evaluated, that is, vulnerability assessment. The variety of hazards, differences in exposures, and complexity of environments make extremely difficult an accurate quantitative evaluation of vulnerability to multi-hazards. The most common method for vulnerability assessment in multiple hazard research at the global scale involves index-based methods in which fragility, adaptability or coping capability, and other vulnerability characteristics are calculated using different indicators and integrated to achieve an indirect reflection of degree of vulnerability (UNDP 2004; UNU-EHS 2013; JRC 2014). The index-based method is easily operable, but shows only relative instead of quantitative results. Vulnerability assessment based on the mortality rate or the economic losses caused by hazards helps to obtain a measure of absolute risk, namely the expected loss value. In the Hotspots Project, a vulnerability evaluation was conducted according to the mortality rate or the economic losses caused by natural hazards at the global level in order to evaluate the risk of deaths and economic losses at a $2.5^{\circ} \times 2.5^{\circ}$ grid scale (Dilley et al. 2005).

In the World Atlas of Natural Disaster Risk, Shi and Kasperson (2015) developed an expected annual multi-hazard intensity $\left(M_{h}\right)$ model to calculate the expected annual affected population risk $\left(M_{h} R I\right)$ caused by a suite of multiple hazards. The $M_{h}$ is based on the probability distribution of 11 individual hazards: earthquakes, volcanic eruptions, landslides, floods, storm surges, tropical cyclones, sand and dust storms, droughts, heat waves, cold waves, and wildfires. Equations 1 and 2 show the method for calculating the $M_{h}$ (Shi and Kasperson 2015).

$\overline{h_{i}}=\frac{h_{i}-h_{i \min }}{h_{i \max }-h_{i \min }} \times 100 \%$
$M_{h}=\sum_{i=1}^{n} \overline{h_{i}} \times w_{i}$

where $h_{i}$ is the expected annual intensity index of hazard $i$-for example, the expected annual intensity of cold wave is the expectation of the largest temperature drop $\left({ }^{\circ} \mathrm{C}\right)$ with return periods of $10,20,50$, and 100 years at each $0.5^{\circ} \times 0.5^{\circ}$ grid unit (Shi and Karsperson 2015); $h_{i \min }$ and $h_{i \max }$ are the minimum and maximum values of the expected annual intensity of hazard $i$, respectively; $w_{i}$ is the weight of hazard $i$, which was calculated based on the frequency of hazards in EM-DAT (EM-DAT 2015) and Zheng (2009) (Table 1); and $n$ is the number of evaluated natural hazards. Compared with previous multi-hazard risk models, the expected annual multi-hazard intensity model can characterize and normalize the spatial pattern of the integrated intensity of multiple hazards and can also reflect the impact of the expected annual intensity of multiple hazards on the population spatially. 
Table 1 Hazard intensity index and weight of each hazard when calculating $M_{h}$

\begin{tabular}{lllr}
\hline$i$ & Natural hazard & Expected annual intensity index & Weight $(\%)$ \\
\hline 1 & Floods & Accumulated three-day extreme precipitation $(\mathrm{mm})$ & 35.86 \\
2 & Tropical cyclones & Speed of 3-second gust wind $(\mathrm{m} / \mathrm{s})$ & 30.23 \\
3 & Earthquakes & Peak ground acceleration $\left(\mathrm{m} / \mathrm{s}^{2}\right)$ & 9.03 \\
4 & Landslides & Landslide hazard index & 5.65 \\
5 & Droughts (maize) & Normalized cumulative water stress index during the crop's growing season & 2.10 \\
& Droughts (wheat) & & 0.52 \\
& Droughts (rice) & & 1.73 \\
6 & Heat waves & Maximum temperature $\left({ }^{\circ} \mathrm{C}\right)$ & 1.77 \\
7 & Cold waves & Largest temperature drop $\left({ }^{\circ} \mathrm{C}\right)$ & 2.99 \\
9 & Volcanos & Volcanic explosivity index & 2.21 \\
10 & Wildfires (forest) & Ignition probability $(\%)$ & 1.38 \\
11 & Wildfires (grassland) & & 0.88 \\
\hline
\end{tabular}

Source Shi and Karsperson (2015)

The high weight values of floods and tropical cyclones are primarily due to their high occurrence frequencies globally. Earthquakes frequently happen in the circumPacific, Alpine-Himalayan, and mid-ocean ridge regions, which also result in a high weight. Frequent occurrences of floods and earthquakes induce landslides, thus the weight for landslides is high too. Due to their relatively low frequencies globally, the other types of hazard have a total weight value of less than $20 \%$. Despite this, given their dominant roles as primary hazards and severe impacts in some regions of the world-for example, the importance of droughts in Africa-these hazards can contribute significantly to the $M_{h}$ index values.

Based on the $M_{h}$ model output and a series of other data and assessment methods, this study assessed the global mortality and affected population risks for the periods 2005-2015 and 2020-2030 at the $0.5^{\circ} \times 0.5^{\circ}$ grid scale and mortality and affected population rates (unit: $10^{5}$ people) for the periods 2005-2015 and 2020-2030 at the national scale. Then, the criteria or threshold values for assessing "substantial reduction" of the two rates were defined by comparing the global average change of rates for these two periods. The result helps highlight the hotspots of natural disasters, improves understanding of the mortality and affected population targets of the SFDRR, and supports the quantitative monitoring and reporting process of the SFDRR.

\section{Data and Methods}

To assess the mortality and affected population risks during 2005-2015 and 2020-2030, the vulnerability model involving $M_{h}$, coping capacity, and mortality rate or affected population rate is developed. The datasets used in this study are listed in Table 2.

Vulnerability is a measure of both the sensitivity of population to natural hazards and its ability to respond to and recover from the impacts of those hazards (Cutter 2006). Generally, a vulnerability model can be defined as a function that includes both a coping capacity (social factor) and a natural hazards component (natural factor) (UNISDR 2004; Esty et al. 2005; Cutter and Christina 2008; UNU-EHS 2013). The Europe Commission Joint Research Centre developed the INFORM model by choosing 13 indicators, such as government effectiveness, corruption perception index, adult literacy rate, to calculate the Lack of Coping Capacity Index for 191 countries (JRC 2014). But a coping capacity index at a finer grid scale is still not available. A significant correlation is found between GDP per capita and the Lack of Coping Capacity Index at the 0.01 confidence level (bilateral) with Pearson correlation coefficients of -0.719 (Fig. 1). Thus, in this study, GDP per capita was selected as the representative indicator of the social factor. The $M_{h}$ was selected as the representative indicator of the natural factor, since this index integrated various hazards with different return periods and intensities.

The vulnerability model is developed by considering $M_{h}$, the coping capacity indicator (GDP per capita), and mortality rate or affected population rate, as shown in Eqs. 3 and 4.

$$
\begin{aligned}
& M R=f\left(M_{h}, G D P_{p}\right) \\
& A R=g\left(M_{h}, G D P_{p}\right)
\end{aligned}
$$

where $M R$ is the mortality rate for multiple natural hazards; $A R$ is the affected population rate for multi-hazards; $M_{h}$ is 
Table 2 Sources and description of the datasets used for calculating global mortality risk and affected population risk

\begin{tabular}{|c|c|c|c|}
\hline Dataset & Data source & Resolution & Time \\
\hline $\begin{array}{l}\text { Expected multi-hazard } \\
\text { intensity index }\left(M_{h}\right)\end{array}$ & World Atlas of Natural Disaster Risk (Shi and Karsperson 2015) & $0.5^{\circ} \times 0.5^{\circ}$ & - \\
\hline $\begin{array}{l}\text { Death toll and affected } \\
\text { population }\end{array}$ & Emergency Events Database (EM-DAT 2015) & $\begin{array}{l}\text { National } \\
\text { unit scale }\end{array}$ & 1980-2014 \\
\hline $\begin{array}{l}\text { Population and GDP density } \\
\text { (grid unit) }\end{array}$ & $\begin{array}{l}\text { Greenhouse Gas Initiative (GGI) Program of the International Institute for } \\
\text { Applied Systems Analysis (IIASA 2005) }\end{array}$ & $0.5^{\circ} \times 0.5^{\circ}$ & $\begin{array}{l}2000,2010,2020 \\
\text { and } 2030^{\mathrm{a}}\end{array}$ \\
\hline $\begin{array}{l}\text { Population and GDP } \\
\text { (national scale) }\end{array}$ & World Bank (2015) & National & 1980-2014 \\
\hline
\end{tabular}

${ }^{a}$ In the GGI database, the time interval of population and GDP data is 10 years, therefore the population and GDP data in 2005 and 2015 are represented by the average values of 2000 and 2010 and of 2010 and 2020, respectively

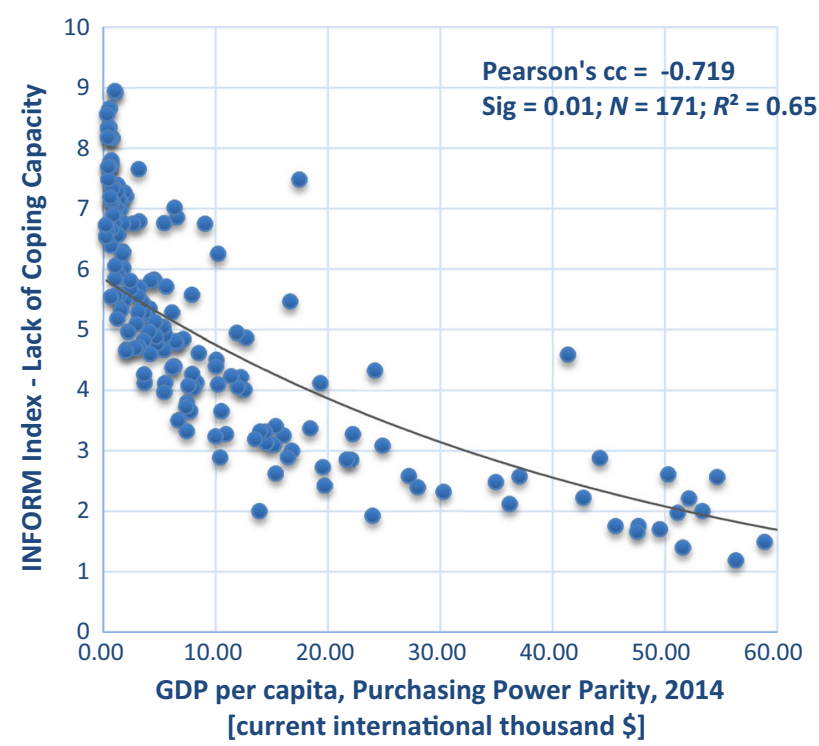

Fig. 1 Comparison of INFORM 2015 Lack of Coping Capacity Index with GDP per capita. Source JRC (2014)

the expected annual intensity of multi-hazards; and $G D P_{p}$ is the coping capacity indicator (GDP per capita) of the country or region.

To build the vulnerability model, the historical mortality and total affected population data in the EM-DAT disaster database between 1980 and 2009 were selected as the training sample to estimate the parameters of the regression model. The result is shown in Eqs. 5 and 6. Significant correlation is found at the 0.01 confidence level $(N=154)$.

$\ln (M R)=-9.77 \times 10^{-6} \times G D P_{p}+9.371 \times \overline{M_{h}}-14.512$

$\ln (A R)=-1.58 \times 10^{-4} \times G D P_{p}+7.73 \times \overline{M_{h}}-5.984$

where $\overline{M_{h}}$ is the average value of the expected annual intensity of multiple hazards of the country or region. We used the expected annual losses to express the risk for multiple natural hazards, as shown in Eqs. 7 and 8.
$R_{M}=M R \times P O P$

$R_{A}=A R \times P O P$

where $R_{M}$ is the mortality risk for multiple natural hazards (persons per year); $R_{A}$ is the affected population risk for multiple natural hazards (persons per year); and $P O P$ is the total population of a country or region. The computational formulas for mortality risk and affected population risk are then given by Eqs. 9 and 10:

$R_{M}=P O P \times e^{\left(-9.77 \times 10^{-6} \times G D P_{p}+9.371 \times \overline{M_{h}}-14.512\right)}$
$R_{A}=P O P \times e^{\left(-1.58 \times 10^{-4} \times G D P_{p}+7.73 \times \overline{M_{h}}-5.984\right)}$

The mortality and total affected population data in the EM-DAT historical disaster database between 2010 and 2014 were selected as the validation sample. A significant correlation between the total risks derived from Eqs. 9 and 10 and the actual mortality and affected population data in the EM-DAT historical database was found at the 0.01 confidence level (bilateral), with Pearson correlation coefficients of 0.45 (mortality) and 0.68 (affected population) (166 countries were included in the analysis since the mortality and affected population data of other countries are not recorded for this period).

We assumed that the correlation between mortality rate or affected population rate and $M_{h}$ and coping capability at the $0.5^{\circ} \times 0.5^{\circ}$ grid scale is the same as that at the national scale. Thus, by replacing $\overline{M_{h}}$ with $M_{h}$, and national total population with population of each grid, Eqs. 9 and 10 can be used to calculate the mortality risk and affected population risk at the grid scale, respectively.

Because the actual mortality and affected population rates data are accessible in EM-DAT only for the period 2005-2015 for country units and subnational data are not available, in order to derive the baseline for progress assessment and project the risks for the 2020-2030 period, we used Eqs. 9 and 10 -but replacing $\overline{M_{h}}$ with $M_{h}$ and national total population with population of each grid-to 


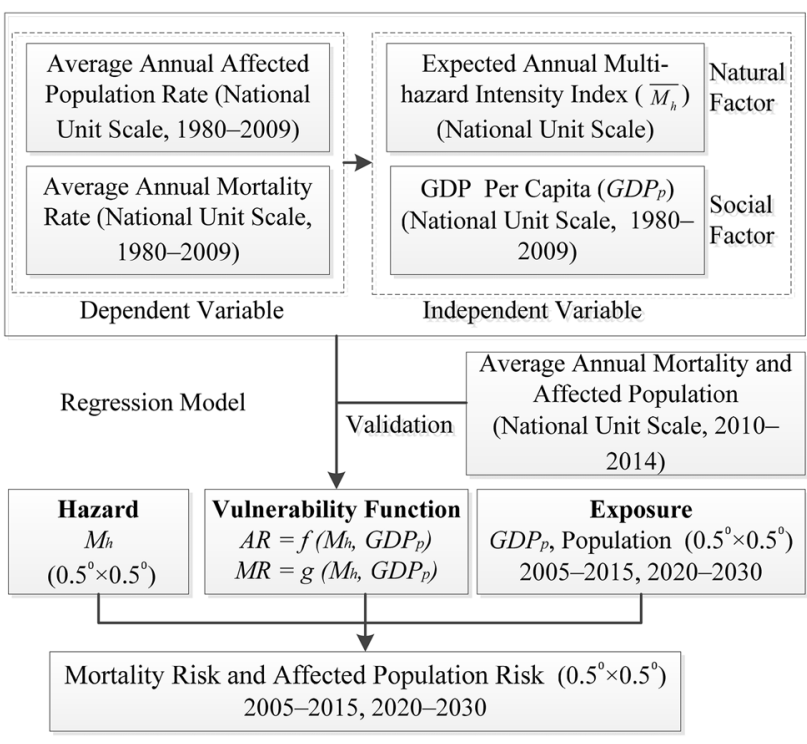

Fig. 2 Flowchart for calculating the global mortality and affected population risks for multiple natural hazards

calculate the risks for each $0.5^{\circ} \times 0.5^{\circ}$ grid for the periods 2005-2015 and 2020-2030. To validate the simulated grid level baseline (2005-2015) result, we calculated the average risks of each country (the mean value of all the grids belong to a country) and correlated them with actual mortality and affected population data for the country units. A significant correlation between the average risk results and the actual rates in EM-DAT was found at the 0.01 confidence level (bilateral), with Pearson correlation coefficients of 0.24 (mortality) and 0.47 (affected population) for the 166 countries that were included. Thus, the results for the period 2005-2015 at the grid scale can be used as baseline for the assessment.

The flowchart for calculating the global mortality and affected population risks for multiple natural hazards is shown in Fig. 2.

\section{Results}

Based on the modified Eqs. 9 and 10, population data $\left(0.5^{\circ} \times 0.5^{\circ}\right)$ and GDP data $\left(0.5^{\circ} \times 0.5^{\circ}\right)$ (IIASA 2005), and annual multi-hazard intensity $\left(M_{h}\right)\left(0.5^{\circ} \times 0.5^{\circ}\right)$ (Shi and Karsperson 2015) were used to calculate the global expected annual mortality risk and affected population risk (2020-2030) for multiple natural hazards by GIS tools. Then the expected annual mortality rate and expected annual affected population rate of countries were calculated (unit: $10^{5}$ people). The results are presented in Figs. 3 and 4 at the $0.5^{\circ} \times 0.5^{\circ}$ grid scale and in Table 3 at the national scale.

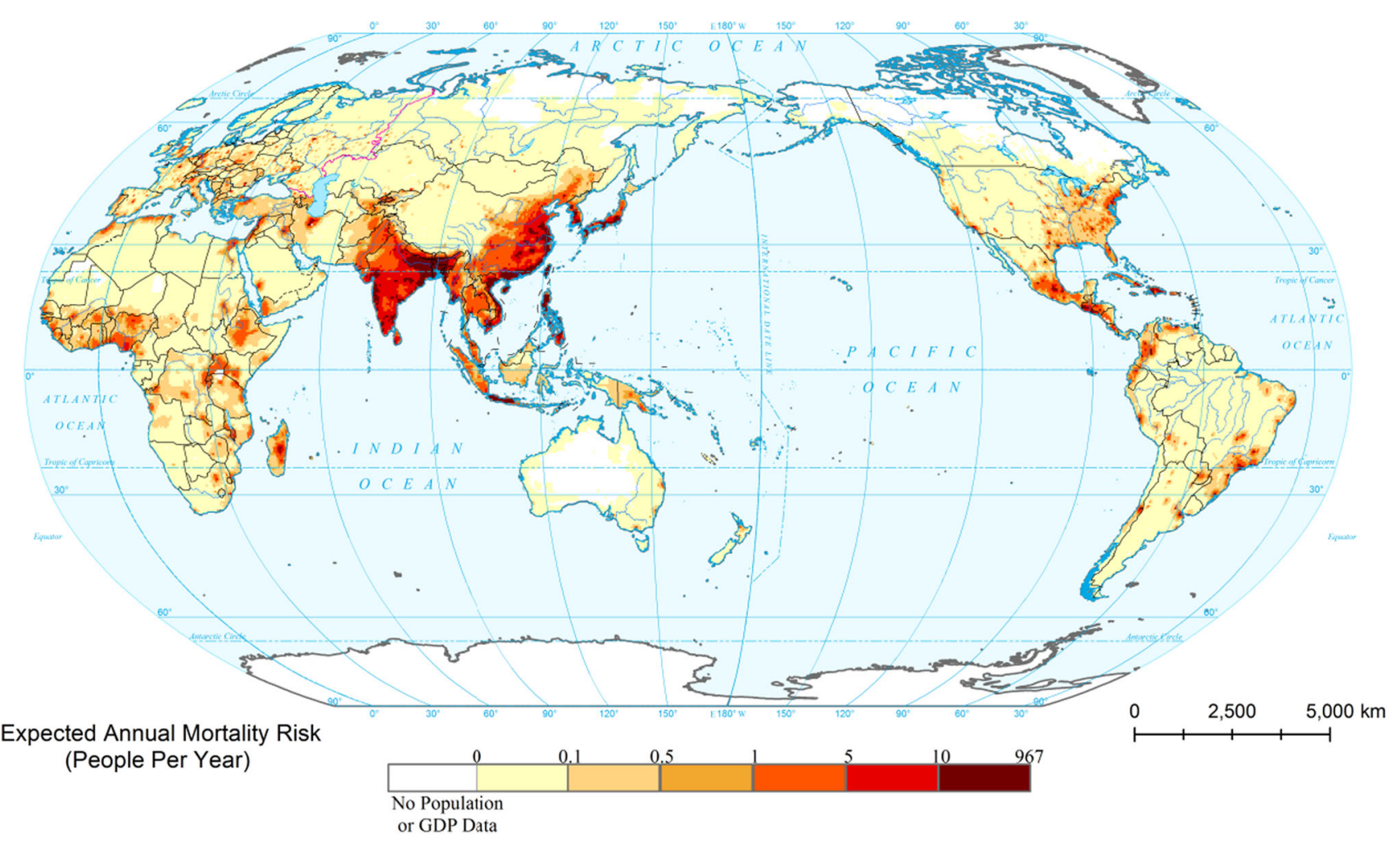

Fig. 3 Global expected annual mortality risk for multiple natural hazards $(2020-2030)\left(0.5^{\circ} \times 0.5^{\circ}\right)$ 


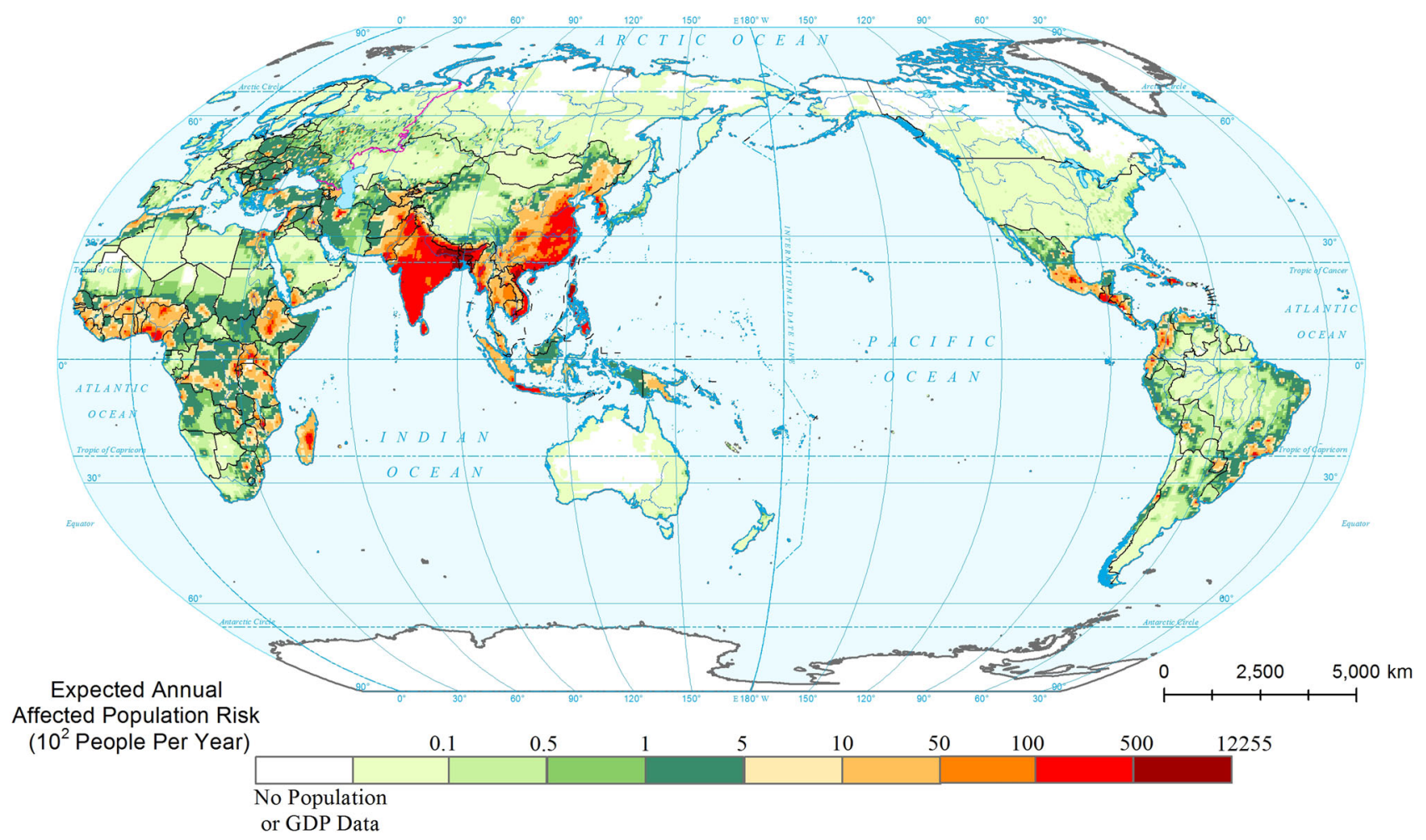

Fig. 4 Global expected annual affected population risk for multiple natural hazards $(2020-2030)\left(0.5^{\circ} \times 0.5^{\circ}\right)$

\subsection{Mapping}

Figures 3 and 4 show the spatial distribution of the global expected annual mortality risk and affected population risk (2020-2030) for multiple natural hazards at the $0.5^{\circ} \times 0.5^{\circ}$ grid scale, respectively.

At the $0.5^{\circ} \times 0.5^{\circ}$ grid scale, regions with the highest expected annual mortality risk are concentrated in the low latitude areas, especially around the Western Pacific and Indian Oceans. Regions of high annual affected population risk only show a slightly different spatial distribution.

\subsection{Ranking}

The top twenty countries with the highest $\overline{M_{h}}$, expected annual multi-hazard mortality rate, and expected annual multi-hazard affected population rate (2020-2030) are listed in Table 3.

At the national scale, countries with both the highest $\overline{M_{h}}$ and low GDP per capita, such as Bangladesh, the Philippines, Laos, and Vietnam, rank the highest for both expected annual mortality and affected population rates. Countries with high GDP per capita and high $\overline{M_{h}}$, such as Japan and South Korea, rank lower for the affected population rate, but high for the mortality rate because of the high $\overline{M_{h}}$ values.

\section{Discussion and Conclusion}

The ranking of national mortality and affected population rates can reflect the vulnerability of a country to multihazards, that is, the degree to which a country is impacted. It can be seen from Eqs. 5 and 6 that the main factors affecting the mortality and affected population rates under multiple natural hazards are GDP per capita (negatively correlated) and multi-hazard intensity (positively correlated). The difference between mortality rate and affected population rate rankings are related to the $\overline{M_{h}}$ and GDP per capita. Equations 5 and 6 show that $\overline{M_{h}}$ has a greater impact than GDP per capita on mortality rate, and GDP per capita affect more than $\overline{M_{h}}$ on affected population rate. According to Table 3, countries and regions around the Pacific and Indian Oceans with high multi-hazard intensity and high population density experience high mortality and affected population rates. For countries and regions with high multiple hazard intensity but low socioeconomic status, mortality rates and affected population rates are very high — that is, high $\overline{M_{h}}$ and low GDP per capita together could lead to both high mortality and high affected population rates. An example of countries under this condition is Bangladesh, which ranks among the highest in both rate categories. High $\overline{M_{h}}$ and high GDP per capita together could lead to lower affected population rate, but they may 
Table 3 Ranking of $\overline{M_{h}}$, expected annual mortality rate, and expected annual affected population rate for multi-hazards at the national scale in descending order (2020-2030)

\begin{tabular}{|c|c|c|c|c|c|c|c|c|}
\hline \multicolumn{3}{|l|}{$\overline{M_{h}}$} & \multicolumn{3}{|c|}{ Expected annual mortality rate } & \multicolumn{3}{|c|}{ Expected annual affected population rate } \\
\hline Rank & Country name & Index ${ }^{a}$ value & Rank & Country name & $\begin{array}{l}\text { Rate (per } 10^{5} \\
\text { people per year) }\end{array}$ & Rank & Country name & $\begin{array}{l}\text { Rate (per } 10^{5} \\
\text { people per year) }\end{array}$ \\
\hline 1 & Bangladesh & 0.395 & 1 & Philippines & 3.57 & 1 & Bangladesh & 5329 \\
\hline 2 & Vietnam & 0.340 & 2 & Bangladesh & 2.20 & 2 & Philippines & 5043 \\
\hline 3 & Laos & 0.322 & 3 & Vietnam & 1.45 & 3 & Vietnam & 3237 \\
\hline 4 & Belize & 0.322 & 4 & Laos & 1.16 & 4 & Madagascar & 2703 \\
\hline 5 & Guatemala & 0.315 & 5 & Japan & 1.16 & 5 & Laos & 2702 \\
\hline 6 & Burma & 0.303 & 6 & Burma & 1.08 & 6 & Bhutan & 2679 \\
\hline 7 & Philippines & 0.301 & 7 & South Korea & 1.01 & 7 & Guatemala & 2094 \\
\hline 8 & South Korea & 0.294 & 8 & Belize & 1.00 & 8 & Burma & 2058 \\
\hline 9 & Madagascar & 0.286 & 9 & Bhutan & 0.98 & 9 & Nepal & 1885 \\
\hline 10 & Papua New Guinea & 0.278 & 10 & Madagascar & 0.93 & 10 & Dominican Republic & 1852 \\
\hline 11 & Japan & 0.277 & 11 & Dominican Republic & 0.92 & 11 & Papua New Guinea & 1811 \\
\hline 12 & Dominican Republic & 0.272 & 12 & Guatemala & 0.91 & 12 & India & 1794 \\
\hline 13 & El Salvador & 0.272 & 13 & New Caledonia & 0.89 & 13 & Honduras & 1718 \\
\hline 14 & Samoa & 0.270 & 14 & Papua New Guinea & 0.83 & 14 & Haiti & 1630 \\
\hline 15 & Honduras & 0.266 & 15 & El Salvador & 0.69 & 15 & Cambodia & 1581 \\
\hline 16 & Cambodia & 0.258 & 16 & Honduras & 0.67 & 16 & Nicaragua & 1529 \\
\hline 17 & Thailand & 0.250 & 17 & India & 0.66 & 17 & Samoa & 1455 \\
\hline 18 & India & 0.248 & 18 & China & 0.66 & 18 & El Salvador & 1442 \\
\hline 19 & Bhutan & 0.247 & 19 & Cuba & 0.62 & 19 & Belize & 1368 \\
\hline 20 & Haiti & 0.246 & 20 & North Korea & 0.61 & 20 & North Korea & 1250 \\
\hline
\end{tabular}

a Data from Shi and Karsperson (2015)

not lead to lower mortality rate-such as in the case of Japan.

The Sendai Framework target improvements desired (UNISDR 2015) would substantially reduce global disaster mortality by lowering average per 100,000 global mortality and affected population during the 2020-2030 decade compared to 2005-2015. The difficulty in interpreting progress toward achieving Sendai Framework objectives is that the goals are clear, but they are not specific about the quantities; "substantially reduce" and "lower" do not indicate the threshold value of reduction. To better support SFDRR monitoring and reporting of progress quantitatively, threshold values of "substantially reduce the mortality or affected population rate" as a percentage of the baseline values of global average rates for the periods $2005-2015$ by $2020-2030$ are defined in our proposed model: $-1.66 \%$ for mortality rate; and $-11.15 \%$ for affected population rate. By comparing the rates for the periods 2005-2015 and 2020-2030, following conclusions can be drawn:

(1) Global average rates of mortality and affected population are decreasing. This reduction means that most countries can achieve the vaguely defined target of reducing the mortality rate and affected population rate without engaging in special efforts;

(2) Coping capacity for natural hazards of those countries with increasing mortality and affected population rates cannot keep pace with $M_{h}$ and the growth of exposure in our estimated scenario. These countries, such as Bangladesh and Madagascar, should be considered as hotspots in SFDRR implementation;

(3) Other countries with rate changes (reduction) lower than the global average noted in red in Table 4, such as Vietnam and Nepal, could reduce their risk level but less than the global average value. To substantially reduce the rates, disaster risk reduction in these countries should focus on strengthening coping capability, reducing exposure, and enhancing disaster risk governance;

(4) Countries with higher GDP growth rates, which also are linked to a higher growth in coping capability, such as Japan and the Philippines, could reduce the rates substantially in our scenario. For these countries, reducing exposure to natural hazards can reduce the total mortality risk or affected population risk effectively. 
Table 4 Carbohydrate assimilation and growth at $37{ }^{\circ} \mathrm{C}$ of two yeast isolates representative of each RAPD cluster/species; bold: results in contrast with type strain

\begin{tabular}{|c|c|c|c|c|c|c|c|c|c|}
\hline \multicolumn{5}{|c|}{ Mortality Rate (per $10^{5}$ people per year) } & \multicolumn{5}{|c|}{ Affected Population Rate (per $10^{5}$ people per year) } \\
\hline Rank & $\begin{array}{l}\text { Country } \\
\text { Name }\end{array}$ & $\begin{array}{l}2005- \\
2015\end{array}$ & $\begin{array}{l}2020- \\
2030\end{array}$ & $\begin{array}{l}\text { Rate of } \\
\text { Change }\end{array}$ & Rank & $\begin{array}{l}\text { Country } \\
\text { Name }\end{array}$ & $\begin{array}{l}2005- \\
2015\end{array}$ & $\begin{array}{l}2020- \\
2030\end{array}$ & $\begin{array}{l}\text { Rate of } \\
\text { Change }\end{array}$ \\
\hline 1 & Philippines & 3.65 & 3.57 & $-2.12 \%$ & 1 & Bangladesh & 5430 & 5329 & $-1.86 \%$ \\
\hline 2 & Bangladesh & 2.19 & 2.20 & $0.06 \%$ & 2 & Philippines & 6079 & 5043 & $-17.05 \%$ \\
\hline 3 & Vietnam & 1.46 & 1.45 & $-0.27 \%$ & 3 & Vietnam & 3615 & 3237 & $-10.47 \%$ \\
\hline 4 & Laos & 1.18 & 1.16 & $-1.83 \%$ & 4 & Madagascar & 2658 & 2703 & $1.68 \%$ \\
\hline 5 & Japan & 1.24 & 1.16 & $-6.57 \%$ & 5 & Laos & 3034 & 2702 & $-10.95 \%$ \\
\hline 6 & Burma & 1.08 & 1.08 & $-0.25 \%$ & 6 & Bhutan & 2929 & 2679 & $-8.54 \%$ \\
\hline 7 & South Korea & 1.02 & 1.01 & $-0.52 \%$ & 7 & Guatemala & 2286 & 2094 & $-8.42 \%$ \\
\hline 8 & Belize & 1.01 & 1.00 & $-0.28 \%$ & 8 & Burma & 2452 & 2058 & $-16.07 \%$ \\
\hline 9 & Bhutan & 1.07 & 0.98 & $-8.93 \%$ & 9 & Nepal & 1933 & 1885 & $-2.46 \%$ \\
\hline 10 & Madagascar & 0.91 & 0.93 & $1.93 \%$ & 10 & $\begin{array}{l}\text { Dominican } \\
\text { Republic }\end{array}$ & 2181 & 1852 & $-15.07 \%$ \\
\hline \multicolumn{2}{|c|}{ Global Average } & 0.539 & 0.530 & $-1.66 \%$ & \multicolumn{2}{|c|}{ Global Average } & 1204 & 1070 & $-11.15 \%$ \\
\hline
\end{tabular}

Note: The rate of change numbers in red indicate lower than the average global level of reduction; and those in green indicate higher than the average global level of reduction.

The estimated risks for 2005-2015 show the impacts of the current multiple natural hazards on human society. The assessment for 2020-2030, which is an estimated result based on the $M_{h}$ model output and the estimated population and GDP scenarios from the World Bank and the International Institute for Applied Systems Analysis (IIASA), displays the assessment result when policies and strategies for disaster risk reduction remain the same as those of a decade ago, that is, a business as usual scenario. To achieve the targets set in the SFDRR, it will be necessary to strengthen disaster risk governance, especially for those developing countries with both high multi-hazard intensity and large populations.

The results presented in this study have higher spatial resolution than previous studies and can reflect the intensity, frequency, and spatial patterns of multi-hazards and their impacts on human society. We have described the spatial patterns of mortality and affected population risks for multi-hazards at the $0.5^{\circ} \times 0.5^{\circ}$ grid scale and the rates at the national scale for the periods 2005-2015 and 2020-2030. However, the results presented here are only as good as the population and GDP data on which they are based, as well as the multi-hazard intensity estimation at the grid scale since the availability of global data is limited and the quality of disaster and exposure data are difficult to validate. In addition, changes associated with different hazards as a result of global climate and other changes were not considered in this study. Based on the IPCC Special Report on Managing the Risks of Extreme Events and Disasters to Advance Climate Change Adaptation (SREX), extreme weather, climate events, and climatic hazards present complicated spatiotemporal pattern of changes (IPCC 2012). Analysis of hazards without considering climate change effects can lead to an underestimation of the impact of such hazards on human society. The use of only the spatial pattern of multi-hazards and the assessment of mortality and affected population risks without taking into consideration social and cultural factors in the disaster system is another limitation of the analysis presented here. To adequately address these issues, greater amounts of data and further research are needed to explore the mechanisms, processes, and dynamics of disaster systems and to develop effective approaches to and measures for improving the world's capacity to coping with multiple hazards.

Acknowledgments This work was funded by the Innovative Research Group Project of National Natural Science Foundation of China (41321001); the Chinese National Basic Research Program (973 Program): "Global Change and Environmental Risk Relationships and Adaptability Paradigm" (2012CB955404); and the 111 project "Hazard and Risk Science Base at Beijing Normal University" under Grant B08008, Ministry of Education and State Administration of Foreign Experts Affairs, China. We greatly appreciate the reviewers for their valuable comments and suggestions to improve the quality of the article. 
Open Access This article is distributed under the terms of the Creative Commons Attribution 4.0 International License (http://crea tivecommons.org/licenses/by/4.0/), which permits unrestricted use, distribution, and reproduction in any medium, provided you give appropriate credit to the original author(s) and the source, provide a link to the Creative Commons license, and indicate if changes were made.

\section{References}

Cutter, S.L. 2006. Hazards, vulnerability and environmental justice. London: Earthscan.

Cutter, S.L., and F. Christina. 2008. Temporal and spatial changes in social vulnerability to natural hazards. Proceedings of the National Academy of Sciences of the United States of America (PNAS) 105(7): 2301-2306.

Dilley, M., U. Deichmann, and R.S. Chen. 2005. Natural disaster hotspots: A global risk analysis. Washington, DC: World Bank.

EM-DAT (Emergency Events Database). 2015. Natural disaster database. http://www.emdat.be/. Accessed 23 Jan 2015.

Esty, D.C., M. Levy, T. Srebotnjak, and A. de Sherbinin. 2005. Environmental sustainability index: Benchmarking national environmental stewardship. New Haven: Yale Center for Environmental Law \& Policy.

IIASA (International Institute for Applied Systems Analysis). 2005. Greenhouse gas initiative (GGI) program. http://www.iiasa.ac. at. Accessed 20 Apr 2015.

IPCC (Intergovernmental Panel on Climate Change). 2012. IPCC special report on managing the risks of extreme events and disasters to advance climate change adaptation (SREX). Cambridge: Cambridge University Press.
JRC (European Commission Joint Research Centre). 2014. Index for risk management-INFORM. Luxembourg: The European Union.

Shi, P. 2009. Theory and practice on disaster system research-The fifth discussion. Journal of Natural Disasters 18(5): 1-9 (in Chinese).

Shi, P., and R. Karsperson (eds.). 2015. World atlas of natural disaster risk. Heidelberg: Springer.

UNDP (United Nations Development Programme). 2004. Reducing disaster risk: A challenge for development. New York: UNDP.

UNISDR (United Nations International Strategy for Disaster Reduction). 2004. Living with risk: A global review of disaster reduction initiatives. New York: United Nations.

UNISDR (United Nations International Strategy for Disaster Reduction). 2005. Hyogo framework for action 2005-2015: Building the resilience of nations and communities to disasters. A/CONF.206/6. Geneva: UNISDR.

UNISDR (United Nations International Strategy for Disaster Reduction). 2015. Sendai framework for disaster risk reduction 20152030. A/CONF.224/CRP.1. Geneva: UNISDR. http://www. unisdr.org/files/43291_sendaiframeworkfordrren.pdf. Accessed 26 Jan 2016.

UNU-EHS (United Nations University Institute for Environment and Human Security). 2013. World risk report 2013. http://www. worldriskreport.org/fileadmin/WRB/PDFs_und_Tabellen/Worl dRiskReport_2013_online_01.pdf. Accessed 10 Jun 2014.

World Bank. 2015. World Bank open data. http://data.worldbank.org. Accessed 20 Apr 2015.

Zheng, G.C. 2009. Significant historical epic for disaster prevention and reduction in sixty-year of China. Changsha: Hunan People's Publishing House (in Chinese). 